\title{
Socio-economic inequalities in women's fruit and vegetable intakes: a multilevel study of individual, social and environmental mediators
}

\author{
Kylie Ball ${ }^{1, *}$, David Crawford ${ }^{1}$ and Gita Mishra ${ }^{2}$ \\ ${ }^{1}$ Centre for Physical Activity and Nutrition Research, School of Exercise and Nutrition Sciences, Deakin University, \\ 221 Burwood Highway, Burwood, Victoria 3125, Australia: ${ }^{2}$ School of Population Health, University of \\ Queensland, Herston, Queensland, Australia
}

Submitted 5 July 2005: Accepted 8 November 2005

\begin{abstract}
Objective: This study employed a multilevel design to test the contribution of individual, social and environmental factors to mediating socio-economic status (SES) inequalities in fruit and vegetable consumption among women.

Design: A cross-sectional survey was linked with objective environmental data.

Setting: A community sample involving 45 neighbourhoods.

Subjects: In total, 1347 women from 45 neighbourhoods provided survey data on their SES (highest education level), nutrition knowledge, health considerations related to food purchasing, and social support for healthy eating. These data were linked with objective environmental data on the density of supermarkets and fruit and vegetable outlets in local neighbourhoods.

Results: Multilevel modelling showed that individual and social factors partly mediated, but did not completely explain, SES variations in fruit and vegetable consumption. Store density did not mediate the relationship of SES with fruit or vegetable consumption.

Conclusions: Nutrition promotion interventions should focus on enhancing nutrition knowledge and health considerations underlying food purchasing in order to promote healthy eating, particularly among those who are socio-economically disadvantaged. Further investigation is required to identify additional potential mediators of SES-diet relationships, particularly at the environmental level.
\end{abstract}

\author{
Keywords \\ Fruit consumption \\ Vegetable consumption \\ Socio-economic status \\ Multilevel study
}

Despite the health-protective effects of good nutrition, many individuals do not consume diets consistent with existing dietary guidelines ${ }^{1,2}$. Individuals of low socioeconomic status (SES) have been shown in many studies, and using a range of SES indicators, to be at increased risk of consuming diets that are less than optimal ${ }^{3-6}$. For instance, compared with those of higher SES, individuals of lower SES have been found to eat fewer fruits and vegetables, and to choose foods that are lower in fibre and a range of micronutrients, and higher in $\mathrm{fat}^{3-6}$. These socio-economic differentials in diet parallel SES gradients in health outcomes and comprise one key pathway by which SES impacts health. While SES inequalities in diet have been documented, the mechanisms underlying these inequalities are poorly understood. Research into the determinants of dietary behaviours, however, provides some insights into factors that may potentially explain SES inequalities in diet. There is evidence, for example, that individual factors such as nutrition knowledge and health considerations influence food intake ${ }^{7}$, and that these influences are differentially distributed across SES groups ${ }^{8,9}$. However, the extent to which SES variations in such factors account for SES differences in diet remains largely unknown.

Recently, increased attention has been paid to the role of social and environmental influences on food choice. This is consistent with an ecological model of food consumption, in which behaviour is posited to be influenced by the interaction of individual, social and physical environmental variables $^{10}$. Social support for healthy eating, particularly from a partner or other family members, is a key influence on food choice ${ }^{11}$ and has been suggested to vary across SES groups, with those of low SES reporting poorer support ${ }^{12}$. Fewer studies have assessed physical, structural and material environment influences on diet, and studies using objective environmental measures and appropriate multilevel study designs to capture shared environmental features are scarce. None the less, emerging evidence suggests that aspects of local food environments, such as good availability and accessibility of supermarkets or food stores ${ }^{13,14}$ and the availability of healthful food products in stores $^{15}$, are associated with healthier diets among residents. Given that availability and accessibility of affordable healthy 
foods and food stores may be poorer in socio-economically disadvantaged neighbourhoods ${ }^{16,17}$, these represent additional pathways by which SES might influence diet.

There has been no research that has examined the relative contributions of individual, social and objective environmental factors in explaining SES inequalities in diet using a multilevel framework. The aim of the present study was to examine the roles of nutrition knowledge, health considerations, support for healthy eating, and availability of supermarkets and fruit and vegetable stores, in mediating SES gradients in women's intakes of fruits and vegetables. A focus on the socio-economic influences on the diets of women particularly is important for several reasons. Traditionally, studies of the socio-economic distribution of diet and related health outcomes have more often focused on men ${ }^{18-20}$, and hence less is known about the socioeconomic influences on women's diets. In addition, despite their increasing participation in the labour market in recent decades, women are still largely responsible for domestic duties in households, including food purchasing and meal choice and preparation $^{21}$. An understanding of the dietary choices of women may thus provide insights into the diets of entire households/families.

\section{Methods}

\section{Participants}

The analyses presented are based on data collected from 1347 participants who were recruited using a stratified random sampling procedure from 45 Melbourne* neighbourhoods of different SES within the study area, which for practical reasons was defined as the geographical area within approximately $30 \mathrm{~km}$ of the central business district. Based on qualitative pilot data ${ }^{12}$ in which women were asked about their local neighbourhoods, suburbs were used as approximations of neighbourhoods. A suburb is a commonly used unit of geographic classification.

Based on 2001 Census data, the Australian Bureau of Statistics has assigned to suburbs a SEIFA (Socioeconomic Index for Areas) score based on relative disadvantage (considering attributes such as the proportion of residents with low income, low educational attainment and unskilled occupations) ${ }^{22}$. All suburbs within the study area were ranked according to SEIFA score, and grouped into septiles from low to high socio-economic disadvantage. Fifteen suburbs were then drawn at random from each of the lowest, middle and highest septiles. This was done to ensure that women from a range of SES backgrounds were represented. The Australian electoral roll $\nmid$ was then used to draw a random sample of women

*Melbourne is the capital of the State of Victoria, and the city has a population of approximately 3.5 million.

tRegistration on the electoral roll is compulsory for all Australian citizens aged 18 years or older. aged between 18 and 65 years in each of the 45 neighbourhoods. Given differential response rates by SES groups observed in other mail-based health surveys, we oversampled from the low- and mid-SES neighbourhoods relative to the high-SES neighbourhood, by a ratio of $1: 1.2: 1.5$. The sample drawn to receive the diet survey consisted of 2400 women: 645 from high-SES, 780 from mid-SES and 975 from low-SES neighbourhoods. A total of 1136 women responded: 354 from high-, 407 from midand 375 from low-SES neighbourhoods. This response (50\% overall, excluding from the denominator 127 women who had moved/were ineligible) is similar to those obtained in other recent mail-based surveys targeting women $^{23}$. A second independent sample was drawn in the same manner for a separate physical activity survey. All participants completing the surveys were asked if they were willing to complete a second survey, and those agreeing were posted the alternative survey (diet or physical activity). This second phase of the study resulted in an additional 444 diet surveys ( $42 \%$ of those completing the original physical activity survey). Excluding data from 13 women who had recently moved out of the study neighbourhoods, and 220 women who had missing data on one or more study variables, the final sample size was 1347 ( 445 from high-, 517 from mid- and 385 from low-SES neighbourhoods). Non-respondents to both surveys were more likely to live in low-SES neighbourhoods than in mid- or high-SES neighbourhoods.

\section{Measures}

\section{Predictor variable: SES}

Education was used as an indicator of individual SES in this study. Women were asked to self-report their highest education level as either 'No formal qualifications/up to 10 years', '12 years/Trade/Apprenticeship/Certificate/ Diploma' or 'University degree/Higher degree'.

\section{Outcome variables}

Fruit and vegetable intakes were assessed separately by asking 'How many servings of [fruit/vegetables] do you usually eat each day?' (a serving of fruit was defined as 1 medium piece or 2 small pieces of fruit, or 1 cup of diced pieces; a serving of vegetables was defined as 1/2 cup of cooked vegetables or 1 cup of salad vegetables). Response options were 'none', '1 serving', '2 servings', '3-4 servings' (coded 3.5 for analyses) or '5 servings or more' (coded 5). These questions were adapted from the Australian National Nutrition Survey ${ }^{24}$ in which they were shown to adequately discriminate between groups with different fruit and vegetable intakes assessed by 24-hour recall. The test-retest reliability (intraclass correlation; ICC) of these measures, assessed in a separate study of 30 women who completed the survey on two occasions three days apart, was 0.85 for fruit and 0.85 for vegetables. 


\section{Individual mediators}

Nutrition knowledge. An eight-item nutrition knowledge scale was adapted from an existing scale ${ }^{25}$. Respondents answered 'True', 'False' or 'Don't know' to eight statements about the nutrient sources of various foods (e.g. 'Meat, chicken and fish are the best sources of calcium') and the health effects associated with different dietary components (e.g. 'A diet high in fruits and vegetables and low in salt may help prevent high blood pressure'). The number of correct statements was calculated, and dichotomised as all correct or one or more incorrect.

Health considerations. Two items adapted from a previous study ${ }^{9}$ were used to assess health considerations related to diet. Respondents were asked 'When you are deciding what food/groceries to buy when food shopping, how much do you consider - your own health? - the health of other household members?' Responses were averaged across the coded response options ('Not at all' coded as 1, 'A little' as 2, 'Somewhat' as 3 and 'Very much' as 4; responses of not applicable for the household item were omitted and only the score for own health was used for those cases). Responses were dichotomised at the median into low $(<4)$ or high (4) health considerations when purchasing foods.

\section{Social mediators}

Support for bealthy eating. Social support for healthy eating from family was assessed with three items adapted from a well-validated scale ${ }^{26}$ - 'During the past year, how often did members of your family (including partner/spouse): Eat healthy low-fat foods with you? Encourage you to eat healthy low-fat foods? Discourage you from eating unhealthy foods?' The questions were repeated to assess support from 'friends or work colleagues'. Cronbach's $\alpha$ for the summed scales was 0.70 for family and 0.76 for friends/colleagues.

\section{Environmental mediators}

Availability of large supermarkets (defined as those belonging to one of the largest five supermarket chains in Australia) and of fruit and vegetable stores in the 45 neighbourhoods was assessed objectively through searches of online telephone (www.whitepages.com.au) and service directories (www.yellowpages.com.au) in 2004, and cross-checking these listings against company websites and local government/council online registers. The total numbers of supermarkets and fruit and vegetable stores were calculated for each neighbourhood and expressed relative to the population (outlets per 10000 people). Neighbourhood population data were obtained from 2001 Census data ${ }^{22}$.

\section{Covariates}

Based on their established association with diet, age and marital status were also controlled for in analyses.

\section{Procedures}

All women selected for the two surveys (diet, physical activity) were posted a letter advising them they had been selected to take part in a study of women's health behaviours and that they would shortly receive a survey. One week later diet surveys were posted out to 2400 women and physical activity surveys to a separate sample of 2400 women. A standard reminder protocol ${ }^{27}$ was used; i.e. all nonrespondents received a postcard reminder within three weeks and a second reminder with replacement survey package after a further three weeks. All women received several small incentives with their initial survey package.

\section{Statistical analyses}

Since this study collected data at both the individual level (survey data on fruit and vegetable consumption, individual and social influences) and the neighbourhood level (supermarket and fruit and vegetable store density), multilevel statistical modelling was used to analyse data ${ }^{28}$. A two-level linear regression model, with women $(n=1347)$ at level 1 and neighbourhoods $(n=45)$ at level 2, was fitted to estimate the contribution of individual, social and environmental mediators to explaining socio-economic variations in women's intakes of fruit, and in a separate model, of vegetables.

After conducting descriptive and unilevel analyses to investigate the distributions of demographic, socioeconomic, outcome and mediator variables, multilevel modelling analyses were conducted using a series of steps. Firstly, a two-level null model was fitted for each dietary outcome (fruit and vegetable consumption). The null model, which includes only a constant term in the fixed part, is intended as an initial model against which subsequent models can be tested. The ICC for the null model provides an estimate of the proportion of variance in the dietary outcome that is attributable to betweenneighbourhood variation; the remaining variation is between individuals. The next step involved fitting a series of two-level random intercept models to estimate the contributions of mediating variables to explaining variation by individual-level SES in each of the two dietary outcomes. An initial model (Model 1), including the predictor variable, individual-level SES (education) as well as the covariates (age and marital status), was specified to establish the association between individual-level SES and fruit and vegetable consumption (separately), prior to investigating any mediators. The research questions central to this study were then investigated by extending Model 1 to include the fixed effects for proposed mediators, with environmental (Model 2), social (Model 3) and individual (Model 4) variables added sequentially in three separate blocks, representing mediators from the most distal (neighbourhood environment) to the most proximal (individual). This order of entry was selected since it might be proposed that more distal environmental-level factors themselves may influence more proximal individual-level factors. 
Consistent with Baron and Kenny's ${ }^{29}$ conditions for mediation, only those proposed mediators that were significantly associated bivariately with fruit or vegetable intake were included in these models. The ICC was calculated for each model, and changes in the $\beta$ coefficients (expressed in units of standard deviation of the outcome variables) for associations between education and fruit and vegetable intake were observed across models to assess the impact of including additional mediators. All multilevel models were estimated in MLwiN version 2.0 $0^{30}$ using the maximum likelihood method (IGLS).

\section{Results}

Participant characteristics and distributions of fruit and vegetable intakes by socio-economic, covariate and mediator variables are shown in Table 1. Fruit and vegetable intakes tended to be higher among women with higher levels of education, older women, and (for vegetables only) women who were married or living in de facto relationships. Intakes were also higher among women reporting greater health considerations, those with higher nutrition knowledge scores (vegetables only), and those with greater family and friend support for healthy eating. Neighbourhood density of fruit and vegetable was positively correlated with average vegetable intake.

Results of the series of multilevel regression analyses predicting fruit consumption are presented in Table 2 . The null model showed statistically significant variations in fruit intakes at the individual (98.9\% total variance) but not the neighbourhood level (1.1\% variance). Adjusting for covariates, Model 1 showed that women's education level was significantly positively associated with fruit intake. Since no neighbourhood variables were significantly bivariately associated with average fruit intake, these variables were not included as mediators (i.e. no Model 2). Support for healthy eating from both family and friends were included, and found to predict fruit intake in Model 3; inclusion of these variables slightly reduced the residual variance at the individual level. When the single individual variable that was bivariately predictive of fruit intake - health considerations - was included in Model 4, it was found to significantly predict fruit intake, and inclusion of this variable further reduced the residual variance among individuals. However,

Table 1 Distributions and bivariate associations of fruit and vegetable intakes by socio-economic, covariate and mediator variables

\begin{tabular}{|c|c|c|c|}
\hline Variable & $\%$ & $\begin{array}{l}\text { Fruit mean (SD) (overall } \\
\text { mean: } 1.98, S D: 1.15 \text { ) }\end{array}$ & $\begin{array}{c}\text { Vegetable mean (SD) (overall } \\
\text { mean: } 2.28, \text { SD: } 1.18)\end{array}$ \\
\hline \multicolumn{4}{|l|}{ Education } \\
\hline Up to 10 years & 23.3 & $1.82(1.23)^{\mathrm{a}}$ & $2.11(1.25)^{\mathrm{a}}$ \\
\hline 12 years/certificate/trade & 39.7 & $1.98(1.09)^{\mathrm{a}, \mathrm{b}}$ & $2.19(1.13)^{\mathrm{a}}$ \\
\hline University & 37.0 & $2.09(1.16)^{\mathrm{b}}$ & $2.48(1.15)^{\mathrm{b}}$ \\
\hline \multicolumn{4}{|l|}{ Age (years) (mean: 41.8, SD: 12.6) } \\
\hline $18-29$ & 19.8 & $1.89(1.18)^{\mathrm{a}}$ & $2.19(1.17)^{a, b}$ \\
\hline $30-39$ & 27.2 & $1.81(1.13)^{\mathrm{a}}$ & $2.13(1.10)^{\mathrm{a}}$ \\
\hline $40-49$ & 24.9 & $2.01(1.10)^{a, b}$ & $2.39(1.17)^{b}$ \\
\hline $50-65$ & 28.1 & $2.20(1.15)^{\mathrm{b}}$ & $2.39(1.24)^{b}$ \\
\hline \multicolumn{4}{|l|}{ Marital status } \\
\hline Married/de facto & 67.6 & $2.02(1.13)^{\mathrm{a}}$ & $2.36(1.16)^{\mathrm{a}}$ \\
\hline Separated/divorced/widowed & 12.0 & $1.82(1.17)^{\mathrm{a}}$ & $2.06(1.19)^{b}$ \\
\hline Never married & 20.3 & $1.96(1.22)^{\mathrm{a}}$ & $2.15(1.19)^{\mathrm{b}}$ \\
\hline \multicolumn{4}{|l|}{ Nutrition knowledge } \\
\hline Not all correct & 49.3 & $1.96(1.18)^{\mathrm{a}}$ & $2.08(1.13)^{\mathrm{a}}$ \\
\hline All correct & 50.7 & $2.00(1.12)^{a}$ & $2.47(1.19)^{\mathrm{b}}$ \\
\hline \multicolumn{4}{|l|}{ Health considerations } \\
\hline Low consideration & 47.5 & $1.69(1.10)^{\mathrm{a}}$ & $2.00(1.09)^{\mathrm{a}}$ \\
\hline High consideration & 52.5 & $2.25(1.14)^{b}$ & $2.52(1.19)^{b}$ \\
\hline \multicolumn{4}{|l|}{ Family support for healthy eating } \\
\hline Low & 37.0 & $1.79(1.12)^{\mathrm{a}}$ & $2.07(1.14)^{\mathrm{a}}$ \\
\hline Mid & 38.2 & $2.04(1.15)^{b}$ & $2.30(1.17)^{\mathrm{b}}$ \\
\hline High & 24.8 & $2.19(1.16)^{b}$ & $2.55(1.18)^{c}$ \\
\hline \multicolumn{4}{|l|}{ Friends' support for healthy eating } \\
\hline Low & 39.4 & $1.85(1.16)^{\mathrm{a}}$ & $2.18(1.18)^{\mathrm{a}}$ \\
\hline \multirow{3}{*}{ High } & 38.5 & $2.04(1.11)^{b}$ & $2.28(1.13)^{a, b}$ \\
\hline & 22.0 & $2.13(1.19)^{b}$ & $2.44(1.24)^{\mathrm{b}}$ \\
\hline & & \multicolumn{2}{|c|}{ Pearson's correlation } \\
\hline $\begin{array}{l}\text { Neighbourhood supermarket density (per } 10000 \text { residents) } \\
\text { (mean: } 1.32, \text { SD: } 1.16 \text {, range: } 0-5.15)\end{array}$ & & -0.03 & 0.04 \\
\hline $\begin{array}{l}\text { Neighbourhood fruit and vegetable store density (per } 10000 \text { residents) } \\
\text { (mean: } 1.51, \text { SD: } 1.33 \text {, range: } 0-4.85 \text { ) }\end{array}$ & & -0.04 & $0.06^{*}$ \\
\hline
\end{tabular}

SD - standard deviation.

${ }_{a, b, c}$ For categories of the same variable, mean values within a column with unlike superscript letters are different at $P<0.05 / k$, where $k=$ number of comparisons.

${ }^{*} P<0.05$ for Pearson's correlations. 
Table 2 Effects of adjusting for environmental, social and individual variables on associations between women's socio-economic status and fruit consumption in multilevel linear regression models†

\begin{tabular}{|c|c|c|c|c|c|}
\hline \multirow[b]{2}{*}{ Variable } & \multicolumn{5}{|c|}{$\beta$ (SE) } \\
\hline & Null model & Model 1 & Model 2 & Model 3 & Model 4 \\
\hline \multicolumn{6}{|l|}{ Fixed part } \\
\hline $\begin{array}{l}\text { Constant } \\
\text { Education } \\
\text { (base: }<12 \text { years) }\end{array}$ & $0.00(0.028)$ & $-0.383(0.088)$ & $\begin{array}{l}\text { No environmental } \\
\text { mediators tested }\end{array}$ & $-0.597(0.095)$ & $-0.681(0.094)$ \\
\hline 12 years/certificate/trade & & $0.267(0.065)^{*}$ & & $0.236(0.064)^{*}$ & $0.213(0.063)^{*}$ \\
\hline University & & $0.3640 .067^{*}$ & & $0.326(0.067)^{*}$ & $0.286(0.066)^{*}$ \\
\hline \multicolumn{6}{|l|}{ Social mediators } \\
\hline \multicolumn{6}{|c|}{$\begin{array}{l}\text { Family support for healthy eating } \\
\text { (base: Low) }\end{array}$} \\
\hline Mid & & & & $0.173(0.056)^{*}$ & $0.118(0.055)^{*}$ \\
\hline High & & & & $0.264(0.065)^{*}$ & $0.154(0.065)^{*}$ \\
\hline \multicolumn{6}{|c|}{$\begin{array}{l}\text { Friends' support for healthy eating } \\
\text { (base: Low) }\end{array}$} \\
\hline Mid & & & & $0.124(0.055)^{*}$ & $0.122(0.054)^{*}$ \\
\hline High & & & & $0.143(0.066)^{*}$ & $0.106(0.065)$ \\
\hline \multicolumn{6}{|l|}{ Individual mediators } \\
\hline \multicolumn{6}{|l|}{$\begin{array}{l}\text { Health considerations } \\
\text { (base: Low consideration) }\end{array}$} \\
\hline High consideration & & & & & $0.363(0.049)^{*}$ \\
\hline \multicolumn{6}{|l|}{ Random part } \\
\hline Level 2 (Neighbourhoods) & $0.009(0.008)$ & $0.007(0.007)$ & & $0.008(0.007)$ & $0.008(0.007)$ \\
\hline Level 1 (Individuals) & $0.794(0.031)^{\star}$ & $0.756(0.030)^{*}$ & & $0.736(0.029)^{*}$ & $0.707(0.028)^{*}$ \\
\hline Intraclass correlation $\ddagger$ & 0.011 & 0.009 & & 0.011 & 0.011 \\
\hline-2 log likelihood & 3524.5 & 3456.8 & & 3422.5 & 3368.5 \\
\hline
\end{tabular}

$\beta$ - regression coefficient; SE - standard error.

${ }^{\star} P<0.05$ (based on ratio of estimate to its SE).

† Models 1-4 adjusted for covariates age and marital status.

$\ddagger$ Proportion of total variance in fruit consumption that is between neighbourhoods.

although the association between education level and fruit intake was slightly attenuated, it remained statistically significant even in this final model with all mediators included.

Table 3 presents the corresponding results for vegetable intake. In contrast to the model predicting fruit intake, the null model shows significant variability in vegetable intake at the neighbourhood (6.5\%) as well as the individual (93.5\%) level. Education level was significantly positively associated with vegetable intake (Model 1). The single environmental mediator (neighbourhood fruit and vegetable store density) included in Model 2 was not positively associated with vegetable intakes, and inclusion of this variable had only marginal impact on the association of education with intake and on the variance at both individual and neighbourhood levels. Social support from family but not friends was significantly predictive of vegetable intake in Model 3. Both nutrition knowledge and health considerations were positively predictive (Model 4) and the inclusion of these variables reduced the residual variance at the individual level, as well as reducing the strength of the association of education with vegetable intake. However, education remained a significant predictor of vegetable intake in the final model, although only the university-educated group remained significantly different to the base category.

\section{Discussion}

This study is one of only a few multilevel studies of the influences on food intake in which environmental measures were obtained objectively and multilevel analysis was used to explicitly model variance at different levels. The incorporation of multiple potential mediators from different domains, and the relatively large community-based sample, are further strengths. The present results confirm previous evidence ${ }^{3-6}$ of strong SES differences in fruit and vegetable intakes. The findings also advance those of previous studies by showing that education-level variations in fruit and vegetable intakes were partly mediated by selected social and individual variables, but not by the two neighbourhood-level variables studied.

Previous evidence, largely derived from qualitative studies, indicates that women of lower SES less often choose foods on the basis of health considerations than women of higher SES 9 . The present findings suggest this may be a potentially important mechanism underlying SES variations in fruit and vegetable intakes. Similarly, nutrition knowledge, previously demonstrated to be poorer among those of low $\mathrm{SES}^{8}$, explained some of the association of SES with vegetable (but not fruit) intakes in the present study. Nutrition promotion strategies that focus on the importance of considering health and 
Table 3 Effects of adjusting for environmental, social and individual variables on associations between women's socio-economic status and vegetable consumption in multilevel linear regression models $\dagger$

\begin{tabular}{|c|c|c|c|c|c|}
\hline \multirow[b]{2}{*}{ Variable } & \multicolumn{5}{|c|}{$\beta$ (SE) } \\
\hline & Null model & Model 1 & Model 2 & Model 3 & Model 4 \\
\hline \multicolumn{6}{|l|}{ Fixed part } \\
\hline Constant & $-0.017(0.041)$ & $-0.213(0.090)$ & $-0.246(0.096)$ & $-0.413(0.102)$ & $-0.530(0.099)$ \\
\hline \multirow{2}{*}{\multicolumn{6}{|c|}{$\begin{array}{l}\text { Education } \\
\text { (base: }<12 \text { years) }\end{array}$}} \\
\hline & & & & & \\
\hline 12 years/certificate/trade & & $0.131(0.064)^{*}$ & $0.128(0.064)^{\star}$ & $0.104(0.064)$ & $0.063(0.063)$ \\
\hline University & & $0.329(0.067)^{*}$ & $0.322(0.068)^{*}$ & $0.289(0.067)^{*}$ & $0.202(0.068)^{*}$ \\
\hline Neighbourhood fruit and & & & $0.027(0.027)$ & $0.022(0.027)$ & $0.016(0.025)$ \\
\hline \multicolumn{6}{|l|}{$\begin{array}{l}\text { vegetable store density } \\
\text { (per } 10000 \text { residents) }\end{array}$} \\
\hline \multicolumn{6}{|l|}{ Social mediators } \\
\hline \multirow{2}{*}{\multicolumn{6}{|c|}{$\begin{array}{l}\text { Family support for healthy eating } \\
\text { (base: Low) }\end{array}$}} \\
\hline & & & & & \\
\hline Mid & & & & $0.152(0.055)^{*}$ & $0.098(0.054)$ \\
\hline High & & & & $0.313(0.063)^{\star}$ & $0.219(0.064)^{*}$ \\
\hline \multicolumn{6}{|c|}{$\begin{array}{l}\text { Friends' support for healthy eating } \\
\text { (base: Low) }\end{array}$} \\
\hline Mid & & & & $0.028(0.054)$ & $0.035(0.053)$ \\
\hline High & & & & $0.093(0.065)$ & $0.072(0.064)$ \\
\hline \multicolumn{6}{|l|}{ Individual mediators } \\
\hline \multicolumn{6}{|l|}{ Nutrition knowledge } \\
\hline All correct & & & & & $0.210(0.048)^{*}$ \\
\hline \multicolumn{6}{|l|}{$\begin{array}{l}\text { Health considerations } \\
\text { (base: Low consideration) }\end{array}$} \\
\hline High consideration & & & & & $0.282(0.048)^{*}$ \\
\hline \multicolumn{6}{|l|}{ Random part } \\
\hline Level 2 (Neighbourhoods) & $0.051(0.016)^{\star}$ & $0.031(0.012)^{*}$ & $0.030(0.012)^{\star}$ & $0.033(0.012)^{*}$ & $0.024(0.010)^{\star}$ \\
\hline Level 1 (Individuals) & $0.740(0.029)^{*}$ & $0.719(0.028)^{*}$ & $0.719(0.028)^{\star}$ & $0.700(0.027)^{*}$ & $0.676(0.026)^{*}$ \\
\hline Intraclass correlationł & 0.065 & 0.041 & 0.040 & 0.045 & 0.034 \\
\hline-2 log likelihood & 3465.7 & 3415.9 & 3414.9 & 3380.9 & 3326.9 \\
\hline
\end{tabular}

$\beta$ - regression coefficient; SE - standard error.

${ }^{\star} P<0.05$ (based on ratio of estimate to its SE).

† Models 1-4 adjusted for covariates age and marital status.

$\ddagger$ Proportion of total variance in vegetable consumption that is between neighbourhoods.

nutrition in food selection may therefore help increase fruit and vegetable consumption among low-SES women. Social support for healthy eating has previously been shown to predict food intakes ${ }^{11}$; here it was also found to attenuate associations of education with intakes of fruit (both family and friends) and vegetables (family only). Involving entire families or peers in nutrition promotion programmes may represent another strategy for reducing SES inequalities in diet and promoting fruit and vegetable intakes.

The density of fruit and vegetable stores in the women's local neighbourhoods was not associated with fruit intakes, and there were only weak bivariate associations of store density with vegetable intakes, which were not significant mediators in the multilevel model. These findings suggest that the higher fruit and vegetable intakes amongst the more highly educated women were not attributable to a greater density of supermarkets or fruit and vegetable stores in their local area. This appears inconsistent with findings of the single previous multilevel study $^{13}$ that linked contextual environmental factors with individual food intakes and found significant associations between these factors.
There are several possible explanations for the lack of associations of the environmental factors with diet in the present study. First, the definition of 'neighbourhood' was informed by pilot work in which women typically referred to their suburb when questioned about their local neighbourhood food environment ${ }^{12}$. However, suburbs are considerably larger than the census-tract-defined neighbourhoods used previously ${ }^{13}$, and may have been too large to accurately capture those neighbourhood environmental exposures most salient to residents. A second possibility is that store density may not be the most relevant environmental factor impacting access to fruits and vegetables in this population. Other environmental indicators, such as store proximity or accessibility (e.g. access to private or public transport), or the quality or cost of fruits and vegetables, may be of greater consequence. This hypothesis is supported, at least for vegetable consumption, by the finding that there remained significant neighbourhood-level variation in vegetable intakes even after controlling for fruit and vegetable store density. Finally, the lack of associations of environmental factors with fruit and vegetable intakes may indicate that factors outside the environmental domain are more 
important. This is consistent with our finding that there existed greater variability in vegetable and particularly fruit intake at the individual level than at the neighbourhood level, which also corroborates findings of a previous Australian study of food purchasing behaviour ${ }^{31}$.

Although the individual and social factors examined in this study partly attenuated the relationship of education with fruit and vegetable intakes, the relationship was not completely explained by these variables, as the associations persisted even after controlling for all mediators and covariates. This suggests that other factors not considered here may be important mediators. As well as the additional neighbourhood factors suggested above, self-efficacy, taste preferences, cooking skills, discretionary income or time may also be important mediators of the relationships between education and dietary intake.

As far as we are aware, this is the first study to employ a multilevel design, to investigate individual, social and objectively assessed environmental mechanisms underlying SES differences in dietary intake. However, the study is not without its limitations. The data are based on a crosssectional survey and it is not possible to determine whether the associations observed are causal. In addition, much of the data were self-reported, and social desirability reporting bias is possible. Finally, the study achieved a modest response. However, the repose rate is similar to that achieved in other health surveys, and there is evidence that response rates for most major studies have been falling over the past few decades and that it is not necessary to have high response rates to ensure a broad spectrum of respondents is represented ${ }^{32}$.

In conclusion, the findings suggest that focusing on health purchasing considerations, nutrition knowledge and social support for healthy eating may be important in reducing SES inequalities in women's fruit and vegetable intakes. Further research is required to understand the origins of these social and individual differences across SES groups (i.e. why low-SES groups may have poorer support or lower levels of nutrition knowledge/health considerations). In addition, it will also be important to further explore the role of other environmental variables. Until recently, nutrition promotion initiatives have emphasised psychological models of choice, information provision and individual responsibility ${ }^{33}$. However, in order to achieve good nutrition for all, and particularly among those who are disadvantaged, a more comprehensive understanding of the drivers of socio-economic inequalities in food consumption is required.

\section{Acknowledgements}

This study was partly funded by the National Heart Foundation of Australia. K.B. and D.C. are each supported by National Health and Medical Research
Council/National Heart Foundation Career Development Research Fellowships.

\section{References}

1 US Department of Health and Human Services (DHSS) and US Department of Agriculture (USDA). Dietary Guidelines for Americans 2005. Washington, DC: DHSS and USDA, 2005.

2 National Health and Medical Research Council. Dietary Guidelines for Australian Adults. Canberra: Australian Government Printing Service, 2003.

3 Subar AF, Heimendinger J, Patterson BH, Krebs-Smith SM, Pivonka E, Kessler R. Fruit and vegetable intake in the United States: the baseline survey of the Five A Day for Better Health Program. American Journal of Health Promotion 1995; 9: $352-60$.

4 Ball K, Mishra GD, Thane CW, Hodge A. How well do Australian women comply with dietary guidelines? Public Health Nutrition 2004; 7: 443-52.

5 De Irala-Estevez J, Groth M. A systematic review of socioeconomic differences in food habits in Europe: consumption of fruit and vegetables. European Journal of Clinical Nutrition 2000; 54: 706-14.

6 Johansson L, Thelle DS, Solvoll K, Bjorneboe GEA, Drevon CA. Healthy dietary habits in relation to social determinants and lifestyle factors. British Journal of Nutrition 1999; 81: 211-20.

7 Baranowski T, Weber K, Cullen W, Baranowski J. Psychosocial correlates of dietary intake: advancing dietary intervention. Annual Review of Nutrition 1999; 19: 17-40.

8 Parmenter K, Waller J, Wardle J. Demographic variation in nutrition knowledge in England. Health Education Research 2000; 15: 163-74.

9 Hupkens C, Knibbe R, Drop M. Social class differences in food consumption: the explanatory value of permissiveness and health and cost considerations. European Journal of Public Health 2000; 10: 108-13.

10 Stokols D. Establishing and maintaining healthy environments: toward a social ecology of health promotion. American Psychologist 1992; 47: 6-22.

11 Van Duyn MA, Kristal AR, Dodd K, Campbell MK, Subar AF, Stables G, et al. Association of awareness, intrapersonal and interpersonal factors, and stage of dietary change with fruit and vegetable consumption: a national survey. American Journal of Health Promotion 2001; 16: 69-78.

12 Inglis $\mathrm{V}$, Ball $\mathrm{K}$, Crawford $\mathrm{D}$. Why do women of low socioeconomic status have poorer dietary behaviours than women of higher socioeconomic status? A qualitative exploration. Appetite 2005; 45: 334-43.

13 Morland K, Wing S, Diez Roux A. The contextual effect of the local food environment on residents' diets: the Atherosclerosis Risk in Communities study. American Journal of Public Health 2002; 92: 1761-7.

14 Rose D, Richards R. Food store access and household fruit and vegetable use among participants in the US Food Stamp Program. Public Health Nutrition 2004; 7: 1081-8.

15 Cheadle A, Psaty B, Curry S, Wagner E, Diehr P, Koepsell T, et al. Community-level comparisons between the grocery store environment and individual dietary practices. Preventive Medicine 1991; 20: 250-61.

16 Sooman A, Macintyre S, Anderson A. Scotland's health - a more difficult challenge for some? The price and availability of healthy foods in socially contrasting localities in the west of Scotland. Health Bulletin 1993; 51: 276-84.

17 Morland K, Wing S, Diez Roux A, Poole C. Neighbourhood characteristics associated with the location of food stores and food service places. American Journal of Preventive Medicine 2002; 22: 23-9. 
18 Bartley M, Fitzpatrick R, Firth D, Marmot M. Social distribution of cardiovascular disease risk factors: change among men in England 1984-1993. Journal of Epidemiology and Community Health 2000; 54: 806-14.

19 Fehily AM, Phillips KM, Yarnell JW. Diet, smoking, social class, and body mass index in the Caerphilly Heart Disease Study. American Journal of Clinical Nutrition 1984; 40 $827-33$.

20 Prattala R, Karisto A, Berg MA. Consistency and variation in unhealthy behavior among Finnish men, 1982-1990. Social Science \& Medicine 1994; 39: 115-22.

21 Bittman M. Recent Changes in Unpaid Work. Catalogue No. 4154.0. Canberra: Australian Bureau of Statistics, 1995.

22 Australian Bureau of Statistics (ABS). Census of Population and Housing: Socio-Economic Indexes for Areas (SEIFA) Catalogue No. 2033.0.55.001, Australia. Canberra: ABS, 2003.

23 Brown WJ, Dobson AJ, Bryson L, Byles J. Women's Health Australia: on the progress of the main cohort studies. Journal of Women's Health \& Gender-Based Medicine 1999; 8: 681-8.

24 Australian Bureau of Statistics (ABS). National Nutrition Survey User's Guide 1995. Catalogue No. 4801.1. Canberra: ABS, 1998.

25 Turrell G. Educational differences in dietary guideline food practices: are they associated with educational differences in food and nutrition knowledge? Australian Journal of Nutrition and Dietetics 1997; 54: 25-33.

26 Sallis JF, Grossman RM, Pinski RB, Patterson TL, Nader PR. The development of scales to measure social support for diet and exercise behaviors. Preventive Medicine 1987; 16: 825-36.

27 Dillman DA. Mail and Telephone Surveys: The Total Design Method. New York: Wiley, 1978.

28 Goldstein H. Multilevel Statistical Models, 3rd ed. London: Edward Arnold, 2003.

29 Baron RM, Kenny DA. The moderator-mediator variable distinction in social psychological research: conceptual, strategic, and statistical considerations. Journal of Personality and Social Psychology 1986; 51: 1173-82.

30 Rasbash J, Steele F, Browne W, Prosser B. A User's Guide to MLwiN, Version 2.0. London: Institute of Education, University of London, 2004.

31 Turrell G, Blakely T, Patterson C, Oldenburg B. A multilevel analysis of socioeconomic (small area) differences in household food purchasing behaviour. Journal of Epidemiology and Community Health 2004; 58: 208-15.

32 Krosnick JA. Survey research. Annual Review of Psychology 1999; 50: 537-67

33 Dowler E. Food poverty and food policy. IDS Bulletin. Poverty and Social Exclusion in North and South 1998; 29 $58-65$. 